\title{
The Effect of Hemp (Cannabis sativa L.) Seeds and Hemp Seed Oil on Vascular Dysfunction in Obese Male Zucker Rats
}

\author{
Michał Majewski ${ }^{1, *(\mathbb{D})}$ and Adam Jurgoński ${ }^{2, *(\mathbb{D})}$ \\ 1 Department of Pharmacology and Toxicology, Faculty of Medicine, UWM, 10-082 Olsztyn, Poland \\ 2 Division of Food Science, Institute of Animal Reproduction and Food Research, Polish Academy of Sciences, \\ 10-748 Olsztyn, Poland \\ * Correspondence: michal.majewski@uwm.edu.pl (M.M.); a.jurgonski@pan.olsztyn.pl (A.J.); \\ Tel.: +48-89-524-56-68 (M.M.); +48-89-523-46-01 (A.J.)
}

check for updates

Citation: Majewski, M.; Jurgoński, A. The Effect of Hemp (Cannabis sativa L.) Seeds and Hemp Seed Oil on Vascular Dysfunction in Obese Male Zucker Rats. Nutrients 2021, 13, 2575. https://doi.org/10.3390/nu13082575

Academic Editor: Cristian Del Bo'

Received: 28 June 2021

Accepted: 26 July 2021

Published: 27 July 2021

Publisher's Note: MDPI stays neutral with regard to jurisdictional claims in published maps and institutional affiliations.

Copyright: (c) 2021 by the authors. Licensee MDPI, Basel, Switzerland. This article is an open access article distributed under the terms and conditions of the Creative Commons Attribution (CC BY) license (https:// creativecommons.org/licenses/by/ $4.0 /)$.

\begin{abstract}
Seeds of industrial hemp (Cannabis sativa L.) contain a large amount of protein (26.3\%), dietary fiber $(27.5 \%)$, and fatty acids $(33.2 \%)$, including linoleic, $\alpha$-linolenic, and some amount of $\gamma$-linolenic acid. In our study, obese male Zucker rats $(n=6)$ at 8 weeks of age were supplemented for a further 4 weeks with either ground hemp seeds (12\% diet) or lipid fractions in the form of hemp seed oil ( $4 \%$ diet). Hemp oil decreased blood plasma HDL-cholesterol $(x 0.76, p \leq 0.0001)$, triglycerides $(x 0.55, p=0.01)$, and calculated atherogenic parameters. Meanwhile, hemp seeds decreased HDL-cholesterol $(x 0.71, p \leq 0.0001)$ and total cholesterol $(x 0.81, p=0.006)$ but not the atherogenic index. The plasma antioxidant capacity of water-soluble compounds was decreased by the seeds $(x 0.30, p=0.0015)$, which in turn was associated with a decrease in plasma uric acid ( $x 0.18$, $p=0.03)$. Dietary hemp seeds also decreased plasma urea $(x 0.80, p=0.02)$, while the oil decreased the plasma total protein $(x 0.90, p=0.05)$. Hemp seeds and the oil decreased lipid peroxidation in the blood plasma and in the heart (reflected as malondialdehyde content), improved contraction to noradrenaline, and up-regulated the sensitivity of potassium channels dependent on ATP and $\mathrm{Ca}^{2+}$. Meanwhile, acetylcholine-induced vasodilation was improved by hemp seeds exclusively. Dietary supplementation with ground hemp seeds was much more beneficial than the oil, which suggests that the lipid fractions are only partially responsible for this effect.
\end{abstract}

Keywords: glucose tolerance test; heart rate; mean arterial pressure; NS1619; pinacidil; thoracic aorta; thromboxane-A 2 ; U-46619; Zucker rat

\section{Introduction}

Vascular dysfunction, including compromised vasodilation and vasoconstriction, is an important complication of chronic obesity [1]. Metabolic disorders associated with obesity, such as dyslipidemia, low-grade systemic inflammation, and increased oxidative stress, can lead to the development of atherosclerosis, hypertension, and some other cardiovascular disorders [2]. Therefore, there is a need to find ways to prevent and treat the early development of obesity with its complications. A good experimental model of obesity and vascular dysfunction is homozygous recessive Zucker rats $(f a / f a)$, which have a mutation in a gene-encoding leptin receptor, resulting in a lack of sensitivity to circulating leptin in the blood [1,3]. In Zucker rats, leptin is unable to inhibit neuropeptide $Y$ secretion in the hypothalamus that potentiates appetite, and thus a meaningful increase in dietary intake and body weight is observed together with the occurrence of the aforementioned metabolic disorders [3].

An increased contribution of plant-based food is one of the ways to prevent obesity and associated metabolic disorders, which is partly due to the relatively low caloric value of such food [4]. However, food from plants is also a good source of bioactive compounds that can directly bring benefits to the cardiovascular system, a good example of which are polyunsaturated fatty acids (PUFAs) with $\alpha$-linolenic acid and linoleic acid as their main 
representatives in nature [5]. Besides their nutritional importance, these PUFAs, especially from the n-3 family, can improve lipid metabolism and the inhibition of lipid synthesis in the body $[6,7]$. PUFAs are also believed to prevent lipid accumulation in the arteries and decrease the development of hypertension. However, the consumption of PUFAs can also bring some negative consequences to the body, which especially applies to the fatty acids of the $n-6$ family that can be metabolized to pro-inflammatory eicosanoids [7].

An interesting and relatively less known source of fatty acids is the seeds of industrial hemp (Cannabis sativa L.), as they contain a large amount of PUFAs, including linoleic and $\alpha$-linolenic acids (approx. $53 \%$ and $18 \%$ of total fatty acids) and some small amount of other fatty acids that are uncommon in vegetable oils, such as $\gamma$-linolenic acid [8,9]. The oil from hemp seeds is characterized as having an optimal ratio of n-3 to n-6 PUFAs (1:3), so important for the adequate functioning of the cardiovascular system; however, hemp oil contains trace amounts of trans fatty acids, which are generally thought to raise the risk of atherosclerosis by inhibiting the synthesis of other PUFAs in arterial cells [7,9]. Nevertheless, Al-Khalifa et al. [10] demonstrated that hearts from rats fed with hemp seeds exhibited significantly better postischemic recovery of maximal contractile function and relaxation during reperfusion compared to the control group. The authors concluded that this was due to PUFAs from hemp seeds. However, hemp seeds are also rich in peptides that have been recognized as a potential antihypertensive agent [11] and lignan amides with potential anti-inflammatory and cardiovascular activities [12]. Moreover, in the latest study conducted in one of our laboratories, relatively strong hypolipidemic effects of dietary hemp in genetically obese rats were observed, and the oil fraction was only partially responsible for these effects [9].

The aforementioned findings suggest that the consumption of hemp seeds is beneficial for the cardiovascular system compromised by obesity. However, the extent to which PUFAs derived from hemp seeds can be responsible for these beneficial effects has not yet been studied nor the mechanisms underlying their vascular protection. Thus, we aimed to compare the effects of hemp seeds ( $12 \%$ diet) with the corresponding amount of lipid fractions from hemp seed oil (4\% diet) on the cardio-vascular system in genetically obese Zucker rats. We hypothesized that supplementation with either the seeds or the oil can improve metabolic dysfunction of genetic origin and that the seeds are more effective due to a wider range of potentially bioactive compounds.

\section{Materials and Methods}

\subsection{Drugs and Chemicals}

Acetylcholine chloride, sodium nitroprusside, and noradrenaline hydrochloride were obtained from Sigma-Aldrich (St. Louise, MO, USA); potassium chloride from Chempur (Piekary Śląskie, Poland); pinacidil, NS1619, and U-46619 from Cayman Chemical (Ann Arbor, MI, USA). Stock solutions (10 $\mathrm{mM}$ ) of these drugs were prepared in distilled water, except for noradrenaline, which was dissolved in $\mathrm{NaCl}(0.9 \%)+$ ascorbic acid $(0.01 \% w / v)$ solution; pinacidil, NS-1619 were dissolved in DMSO, and U-46619 in ethanol.

These solutions were stored at $-20^{\circ} \mathrm{C}$, and appropriate dilutions were made in KrebsHenseleit solution (KH in mmol/L: $\mathrm{NaCl} 115 ; \mathrm{CaCl}_{2} 2.5 ; \mathrm{KCl}$ 4.6; $\mathrm{KH}_{2} \mathrm{PO}_{4} 1.2 ; \mathrm{MgSO}_{4} 1.2$; $\mathrm{NaHCO}_{3} 25$; glucose 11.1) on the day of the experiment. The maximal solvent concentration in the medium was less than $0.01 \%(\mathrm{vol} / \mathrm{vol})$. At these concentrations, solvents did not alter the reactivity of the studied arteries.

Hemp seeds were purchased from Ekogram (Zielonki, Poland), and unrefined, coldpressed hemp seed oil was obtained from Ol’Vita (Panków, Poland).

\subsection{Chemical Composition of Hemp Seeds and Hemp Seed Oil}

Following methods were applied: gravimetric method at a high temperature $105^{\circ} \mathrm{C}$ $/ \sim 580^{\circ} \mathrm{C}$ for dry matter (DM) content and ash; enzymatic-gravimetric method for total dietary fiber; Kjeldahl method for crude protein; the Soxhlet extraction for crude fat; and 
gas chromatography with flame ionization detection (Hewlett Packard 5890, Wilmington, DE, USA) for fatty acids methyl esters, as previously described [5].

\subsection{Experimental Protocol}

All efforts were made to minimize animal suffering. Male Zucker rats (Charles River, Sulzfeld, Germany) at 8 weeks of age were randomly allocated to 4 groups ( $n=6 /$ group) and fed for a further 4 weeks with experimental diets in form of pellets. The lean controls (LC) and obese controls (OC) were fed with a standard rat chow, whereas the other 2 obese groups were fed a modified diet in which either hemp seeds (12\% diet; HS) or hemp seed oil ( $4 \%$ diet; $\mathrm{HO}$ ) were included. All these diets were prepared in such a manner so that they had the same amount of carbohydrate (52\%), protein (18\%), fat (8.3\%), and fiber (5\%). Diets fed to the $\mathrm{O}+\mathrm{HS}$ group and $\mathrm{O}+\mathrm{HO}$ group also had a similar fatty acid profile.

The rats were individually housed in plastic cages under a controlled environment (a $12 \mathrm{~h}$ light-dark cycle, a temperature of $21 \pm 1^{\circ} \mathrm{C}$, relative humidity of $50-70 \%$, and 20 air changes per hour) [13].

\subsection{Experimental Procedures}

The mixture of ketamine + xylazine $(100+10 \mathrm{mg} / \mathrm{kg} B W)$ was used for intraperitoneal anesthesia [14]. The whole blood was kept in tubes containing heparin + EDTA as an anticoagulant and centrifuged at $3000 \times g$ for $10 \mathrm{~min}$ to separate the blood plasma, which was stored at $-80{ }^{\circ} \mathrm{C}$ until further analysis. The thoracic arteries were carefully isolated and kept in a Krebs-Henseleit buffer at $+4^{\circ} \mathrm{C}$.

\subsection{Blood and Heart Tissue Analysis}

The traditional blood plasma lipids (the total cholesterol-TC, high-density lipoprotein cholesterol-HDL, triglycerides-TG; mmol/L), gamma-glutamyl transferase (GGT, U/L), uric acid $(\mu \mathrm{mol} / \mathrm{L})$, urea $(\mathrm{mmol} / \mathrm{L})$, creatinine level $(\mu \mathrm{mol} / \mathrm{L})$, albumin $(\mu \mathrm{mol} / \mathrm{L})$, and total protein $(\mathrm{g} / \mathrm{L})$ were measured with a biochemical autoanalyzer (Horiba, Kyoto, Japan) [14].

The malondialdehyde-thiobarbituric acid (MDA-TBA) adduct was quantified at $532 / 553 \mathrm{~nm}(\mathrm{Ex} / \mathrm{Em})$ with a Fluorometric Assay Kit (ab118970), and the values were expressed as $\mu \mathrm{mol} / \mathrm{L}$ of the blood plasma and $\mathrm{ng} / \mathrm{g}$ of heart tissue.

The antioxidant capacity of water- and lipid-soluble compounds of the blood plasma (ACW and ACL, respectively; $\mathrm{mg} / \mathrm{L}$ ) were determined by a photo-chemiluminescence detection method using Photochem (Analytik Jena AG, Germany). This method is based on the generation of free radicals that are partially eliminated through a chemical reaction with antioxidants present in the plasma sample, and the remaining radicals are quantified by luminescence generation. The lipid fraction was separated using methanol, n-hexane, and centrifugation. Calibration curves are based on Ascorbate and Trolox as standards for ACW and ACL, respectively.

\subsection{Glucose Tolerance Test}

Rats were given a $50 \%$ glucose solution by oral gavage ( $2 \mathrm{~g} / \mathrm{kg}$ of body weight) after overnight starvation, 4 days before the final termination. Blood samples were collected from the tail tip, and glucose was measured with a glucometer (Accu-Chek Active, Roche Diagnostics, Germany) at 0, 15, 30, 60, 90, 120, and $180 \mathrm{~min}$.

\subsection{Blood Pressure Measurements}

Mean arterial pressure, MAP ( $\mathrm{mmHg}$ ) and heart rate, $\mathrm{HR}(\mathrm{bpm})$ were monitored on the day before the blood collection with the noninvasive tail-cuff method (LE5001, Panlab, Harvard Apparatus, Barcelona, Spain).

\subsection{Thromboxane- $A_{2}$ Quantification}

This was completed following Majewski et al. [2]. Briefly, after a stabilization period in KHS at $+37^{\circ} \mathrm{C}$ for $30 \mathrm{~min}(\mathrm{pH} 7.4)$, aortic rings from each group of rats were followed 
by 2 wash periods of $10 \mathrm{~min}$ using $200 \mu \mathrm{L}$ of KHS. Once fresh KHS was replaced, arteries were exposed to noradrenaline $(0.1 \mu \mathrm{M}, 2 \mathrm{~min})$ and then to the cumulative acetylcholine concentrations $(0.1 \mathrm{nM}-10 \mu \mathrm{M})$ at 1 min intervals. The medium was collected and stored at $-80^{\circ} \mathrm{C}$ until further analysis. Production of thromboxane- $\mathrm{A}_{2}$ was monitored by measuring the stable metabolite thromboxane- $\mathrm{B}_{2}$. This was completed using the appropriate enzyme immunoassay kit (Cayman Chemical, Ann Arbor, MI, USA). Results are expressed as $\mathrm{pg} / \mathrm{mg}$ of tissue.

\subsection{Vascular Reactivity Studies}

This was previously described in detail by Majewski et al. [14,15]. Briefly, isolated aortic rings of $4 \mathrm{~mm}$ length were aerated in a stagnant $5 \mathrm{~mL}$ Graz Tissue Bath System (Harvard Apparatus, March-Hugstetten, Germany) for $60 \mathrm{~min}$, under $1 \mathrm{~g}$ pre-load tension, and precontracted with noradrenaline $(0.1 \mu \mathrm{M})$. Then, the cumulative concentrations of either acetylcholine $(0.1 \mathrm{nM}-10 \mu \mathrm{M})$, sodium nitroprusside $(0.001 \mathrm{nM}-10 \mu \mathrm{M})$, pinacidil $(10 \mathrm{nM}-10 \mu \mathrm{M})$, or NS-1619 $(1 \mathrm{nM}-10 \mu \mathrm{M})$ were added into the bath chambers to study the vasodilator response. In another set of experiments, vasoconstriction was studied with cumulative concentrations of noradrenaline $(0.1 \mathrm{nM}-10 \mu \mathrm{M})$ and $\mathrm{U}-46619(0.1 \mathrm{nM}-1 \mu \mathrm{M})$.

\subsection{Data Analysis and Statistics}

A nontraditional lipid profile was calculated based on TC, HDL, and TG as $\log _{10}\left(\frac{\mathrm{TG}}{\mathrm{HDL}}\right)$, $\frac{\mathrm{TC}}{\mathrm{HDL}}, \mathrm{TC}$ minus HDL, VLDL (calculated as: $\frac{\mathrm{TG}}{2.2}$ ), LDL (calculated as TC minus HDL minus VLDL), $\frac{\mathrm{TG} * \mathrm{TC} * \mathrm{LDL}}{\mathrm{HDL}}, \frac{\text { nonHDL }}{\mathrm{HDL}}$ and $\frac{\mathrm{LDL}}{\mathrm{HDL}} \cdot \mathrm{Non} H \mathrm{HDL}$ was calculated as TC minus HDL $[14,16,17]$. MAP was calculated as DP $+1 / 3(\mathrm{SP}-\mathrm{DP})$, where DP is the diastolic blood pressure and $\mathrm{SP}$ is the systolic blood pressure.

The contraction induced by high $\mathrm{KCl}(75 \mathrm{mM})$ was expressed in $\mathrm{mg}$ of developed tension; meanwhile, contraction with noradrenaline and U-46619 was expressed as \% of $\mathrm{KCl}$-induced response. Vascular relaxation was expressed as a percentage of the contractile response to noradrenaline NA $(0.1 \mu \mathrm{M})$. This concentration of NA was chosen based on the preliminary studies with cumulative doses of NA added into the incubation chambers. The cumulative concentration-response curves were analyzed by a nonlinear regression model, which determined the area under the curve (AUC), maximal response $\left(E_{\max }, \%\right)$, and the potency $\left(\mathrm{pEC}_{50}\right)$. The group comparison was performed by either a parametric (ANOVA) or non-parametric test (Kruskal-Wallis test), with $n=6$. The Gaussian distribution of residuals and homoscedasticity of variance were tested. The Grubbs' test was performed to detect outliers. The post hoc tests were run only when $\mathrm{F}$ achieved the necessary level of statistical significance $(p \leq 0.05)$. The group comparison was performed by MannWhitney's test. Results are expressed as means \pm SD (and means \pm SEM for vascular studies). This research was randomized and stayed blinded for laboratory analyses. The level of significance was when $p \leq 0.05$.

\section{Results}

The composition of hemp seeds and hemp seed oil was determined in order to prepare the experimental diets. Crude fat was calculated as 100:33.2, so the concentration of hemp seeds was increased three-fold compared with the oil; see Table 1. 
Table 1. The composition of hemp seeds and hemp seed oil ${ }^{1}$.

\begin{tabular}{|c|c|c|}
\hline & Hemp Seeds & Hemp Seed Oil \\
\hline Dry matter (DM), \% & $93.1 \pm 0.07$ & - \\
\hline Crude fat, \% DM & $33.2 \pm 0.36$ & - \\
\hline Dietary fiber, \% DM & $27.5 \pm 0.31$ & - \\
\hline Crude protein, \% DM & $26.3 \pm 0.49$ & - \\
\hline Ash, $\%$ DM & $5.09 \pm 0.01$ & - \\
\hline Nitrogen-free extract, \% DM & $1.05 \pm 0.01$ & - \\
\hline \multicolumn{3}{|l|}{ Fatty acid profile (\%) } \\
\hline Linoleic acid (18:2 n-6) & $52.3 \pm 0.07$ & $52.8 \pm 0.08$ \\
\hline$\alpha$-Linolenic acid (18:3 n-3) & $18.1 \pm 0.04$ & $17.47 \pm 0.03$ \\
\hline Oleic acid (18:1 n-9) & $7.91 \pm 0.11$ & $8.61 \pm 0.05$ \\
\hline Palmitic acid (16:0) & $5.80 \pm 0.01$ & $5.46 \pm 0.01$ \\
\hline$\gamma$-Linolenic acid (18:3n-6) & $4.41 \pm 0.02$ & $4.26 \pm 0.05$ \\
\hline Stearic acid (18:0) & $2.18 \pm 0.01$ & $2.26 \pm 0.01$ \\
\hline cis-11,14-Eicosadienoic acid (20:2 n-6) & $1.61 \pm 0.01$ & $1.52 \pm 0.01$ \\
\hline Vaccenic acid (18:1 n-7) & $0.95 \pm 0.01$ & $0.93 \pm 0.02$ \\
\hline Arachidic acid (20:0) & $0.85 \pm 0.00$ & $0.83 \pm 0.01$ \\
\hline Gondoic acid (20:1 n-9) & $0.41 \pm 0.01$ & $0.38 \pm 0.01$ \\
\hline Behenic acid (22:0) & $0.36 \pm 0.01$ & $0.33 \pm 0.01$ \\
\hline Lignoceric acid (24:0) & $0.15 \pm 0.00$ & $0.13 \pm 0.01$ \\
\hline cis-9,trans-12-Octadecadienoic acid (18:2 n-6) & $0.11 \pm 0.01$ & $0.12 \pm 0.00$ \\
\hline Palmitoleic acid (16:1) & $0.09 \pm 0.00$ & $0.08 \pm 0.01$ \\
\hline \multicolumn{3}{|l|}{ Calculated fatty acid content (\%) } \\
\hline PUFAs & $76.4 \pm 0.12$ & $76.1 \pm 0.03$ \\
\hline$n-3$ & $18.1 \pm 0.04$ & $17.5 \pm 0.02$ \\
\hline$n-6$ & $58.3 \pm 0.09$ & $58.6 \pm 0.02$ \\
\hline MUFAs & $9.37 \pm 0.11$ & $10.0 \pm 0.03$ \\
\hline SFAs & $9.34 \pm 0.02$ & $9.02 \pm 0.01$ \\
\hline TFAs & $0.11 \pm 0.01$ & $0.12 \pm 0.00$ \\
\hline
\end{tabular}

$\overline{{ }^{1} \text { Values are means } \pm \mathrm{SD}(n=3) \text {. DM, dry matter; MUFA, monounsaturated fatty acid; PUFA, polyunsaturated }}$ fatty acid; SFA, saturated fatty acid; TFA, trans fatty acid.

\subsection{The General Characterization of Experimental Animals}

Experimental supplementation with $\mathrm{HO}$ neither changed the body weight (Figure 1A-C) nor the dietary intake (Figure 1D) of obese Zucker rats (x1.00, $p>0.9999$, and $\mathrm{x} 0.98, p=0.94$, respectively), and the same was found for the HS-group of rats ( $\mathrm{x} 0.91, p=0.66$, and $\mathrm{x} 0.99$, $p=0.99$, respectively). No significant difference was observed in HS- vs. HO-supplemented rats $(x 0.91, p=0.68$, and $x 1.01, p=0.99$, respectively); see Table S1.
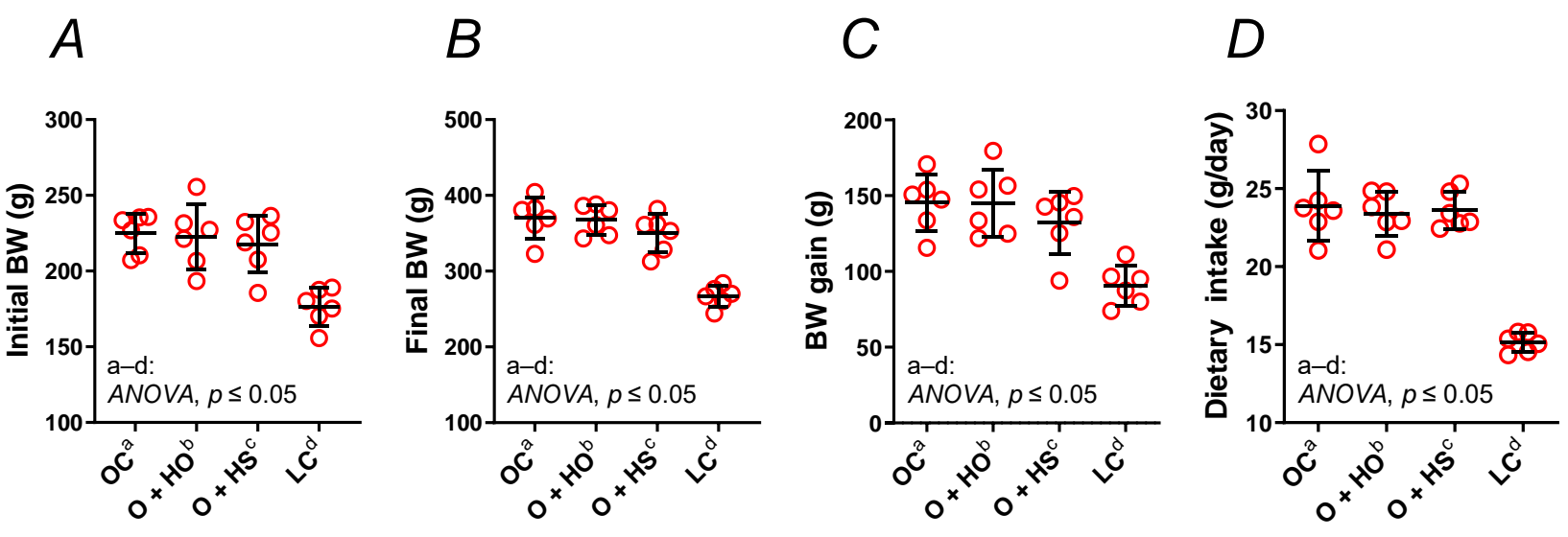

- mean individual values

Figure 1. Body weight (BW) (A-C) and dietary intake (D) of 8-week-old lean (LC) and obese (OC) Zucker rats fed a diet containing hemp seed oil (HO) and hemp seeds (HS) for 4 weeks. Values are means $\pm \mathrm{SD}, n=6, p \leq 0.05$ (two-way ANOVA). Experimental supplementation with $\mathrm{HO}$ and HS neither changed the body weight nor the dietary intake of obese Zucker rats. 


\subsection{The Lipid Profile}

Supplementation with HO significantly decreased both the HDL (x0.76, $p \leq 0.0001)$ and TG $(x 0.55, p=0.01)$, but not the TC $(\mathrm{x} 0.89, p=0.16)$. In contrast, HS decreased the TC $(\mathrm{x} 0.81, p=0.006)$ and the HDL $(\mathrm{x} 0.71, p \leq 0.0001)$ but not the TG $(\mathrm{x} 0.76, p=0.25)$; see Figure 2A-C. No significant difference in the lipid profile was observed in HS- vs. HO-supplemented rats (TC x0.91, $p=0.35 ;$ HDL x0.94, $p=0.6$; TG x1.36, $p=0.4$ ).

$A$

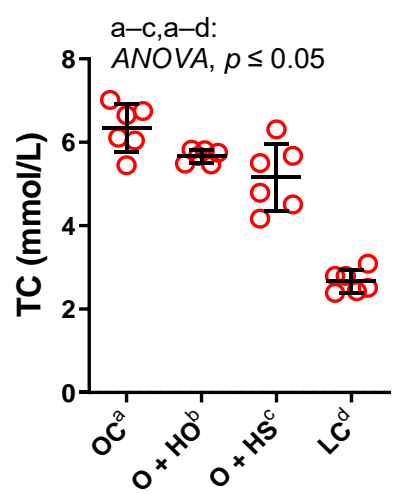

$B$

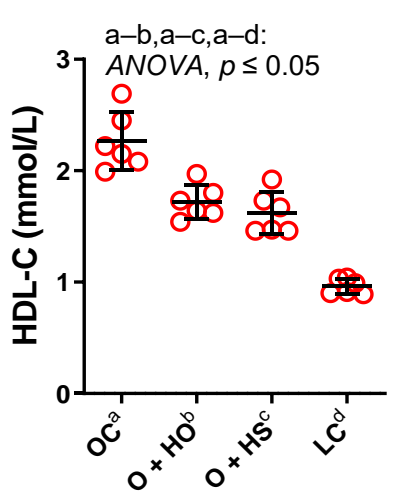

C

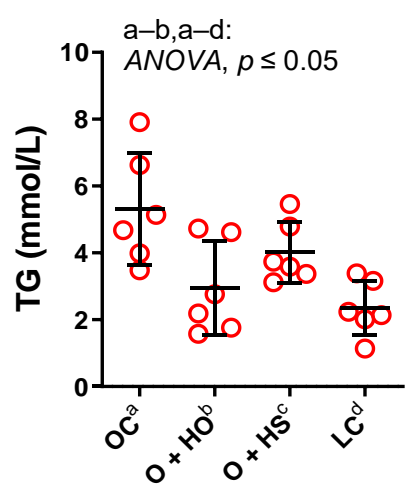

Figure 2. Total cholesterol (TC) (A), high-density lipoprotein cholesterol (HDL-C) (B), and triglycerides (TG) (C) in blood plasma of 8-week-old lean (LC) and obese (OC) Zucker rats fed a diet containing hemp seed oil (HO) and hemp seeds (HS) for a further 4 weeks. Values are means $\pm \mathrm{SD}$, $n=6, p \leq 0.05$ (two-way ANOVA). HO decreased the HDL and TG; meanwhile, HS decreased the HDL and TC.

\subsection{The Calculated Nontraditional Lipid Profile}

TC minus HDL, LDL, $\frac{T G * T C * L D L}{\mathrm{HDL}}$ were not modified by the hemp opposite to the $\log _{10}\left(\frac{\mathrm{TG}}{\mathrm{HDL}}\right), \frac{\mathrm{TC}}{\mathrm{HDL}}, \mathrm{VLDL}, \frac{\mathrm{nonHDL}}{\mathrm{HDL}}$, and $\frac{\mathrm{LDL}}{\mathrm{HDL}}$ (Figure $\left.3 \mathrm{~A}-\mathrm{H}\right)$. The HO decreased VLDL $(\mathrm{x} 0.55, p=0.013)$ and $\log _{10}\left(\frac{\mathrm{TG}}{\mathrm{HDL}}\right)(\mathrm{x} 0.48, p=0.023)$; meanwhile, it increased $\frac{\mathrm{LDL}}{\mathrm{HDL}}(\mathrm{x} 1.80$, $p=0.04), \frac{\mathrm{nonHDL}}{\mathrm{HDL}}(\mathrm{x} 1.28, p=0.016)$, and $\frac{\mathrm{TC}}{\mathrm{HDL}}(\mathrm{x} 1.18, p=0.016)$. The LDL $(\mathrm{x} 1.29, p=0.46)$, TC minus HDL $(x 0.97, p=0.96)$, and $\frac{\mathrm{TG} * \mathrm{TL} C \mathrm{LDL}}{\mathrm{HDL}}(\mathrm{x} 0.91, p=0.94)$ were not modified in a significant way. In contrast, HS did not have any significant effect on the calculated lipid profile $\left(\frac{\mathrm{nonHDL}}{\mathrm{HDL}} \times 1.22, p=0.08 ; \mathrm{LDL} \times 1.21, p=0.91 ; \frac{\mathrm{TC}}{\mathrm{HDL}} \times 1.14, p=0.08 ; \log _{10}\left(\frac{\mathrm{TG}}{\mathrm{HDL}}\right) \times 1.05\right.$, $p=0.99$; TC minus HDL $\times 0.87, p=0.20 ;$ LDL $\times 0.85, p=0.84 ; \frac{\mathrm{TG} * \mathrm{TC} * \mathrm{LDL}}{\mathrm{HDL}} \times 0.85, p=0.79$; VLDL $x 0.76, p=0.25)$. A significant increase in $\log _{10}\left(\frac{\mathrm{TG}}{\mathrm{HDL}}\right)(\mathrm{x} 2.17, p=0.01)$ was observed in HS- vs. HO-supplemented rats. This was not observed for VLDL ( $11.36, p=0.40)$, $\frac{\mathrm{TC}}{\mathrm{HDL}}$ $(\mathrm{x} 0.96, p=0.84), \frac{\text { nonHDL }}{\mathrm{HDL}}(\mathrm{x} 0.95, p=0.84), \frac{\mathrm{TG} * \mathrm{TC} * \mathrm{LDL}}{\mathrm{HDL}}(\mathrm{x} 0.93, p=0.98), \mathrm{TC}$ minus HDL $(\mathrm{x} 0.90$, $p=0.40), \frac{\mathrm{LDL}}{\mathrm{HDL}}(\mathrm{x} 0.67, p=0.17)$, or LDL $(\mathrm{x} 0.66, p=0.10)$; see Table S1.

\subsection{Markers of Antioxidant Status}

Supplementation with $\mathrm{HO}$ neither modified the ACW (x0.80, $p=0.63)$ nor the ACL $(\mathrm{x} 0.80, p=0.45)$; meanwhile, HS decreased ACW $(\mathrm{x} 0.30, p=0.0015)$ but not the ACL $(\mathrm{x} 0.75$, $p=0.25)$. A significant decrease in ACW ( $\mathrm{x} 0.37, p=0.0048)$ was observed in HS- vs. HOsupplemented rats. This was not observed for the ACL ( $0.93, p=0.97)$; see Figure 4A,B and Table S1. 


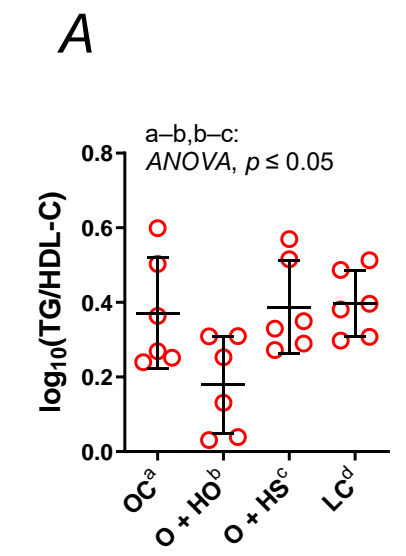

B

C

D
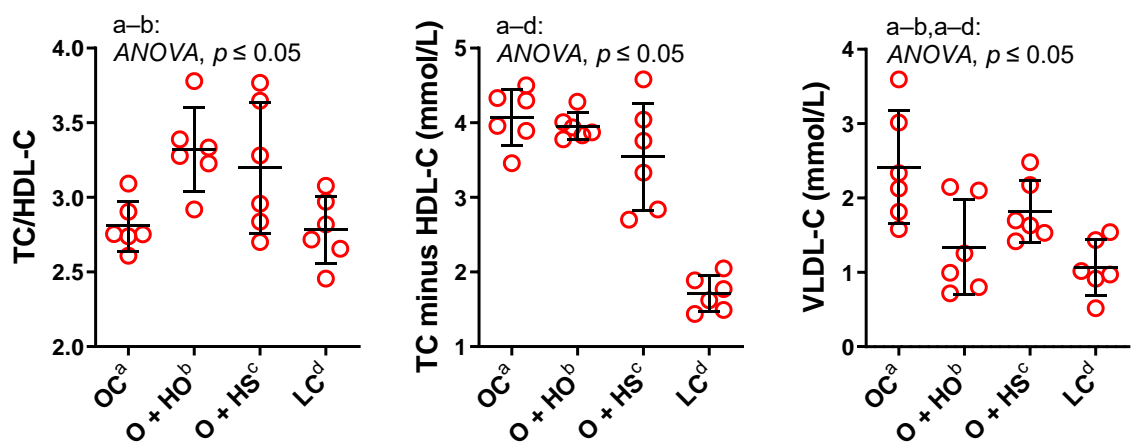

E

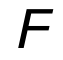

G

H
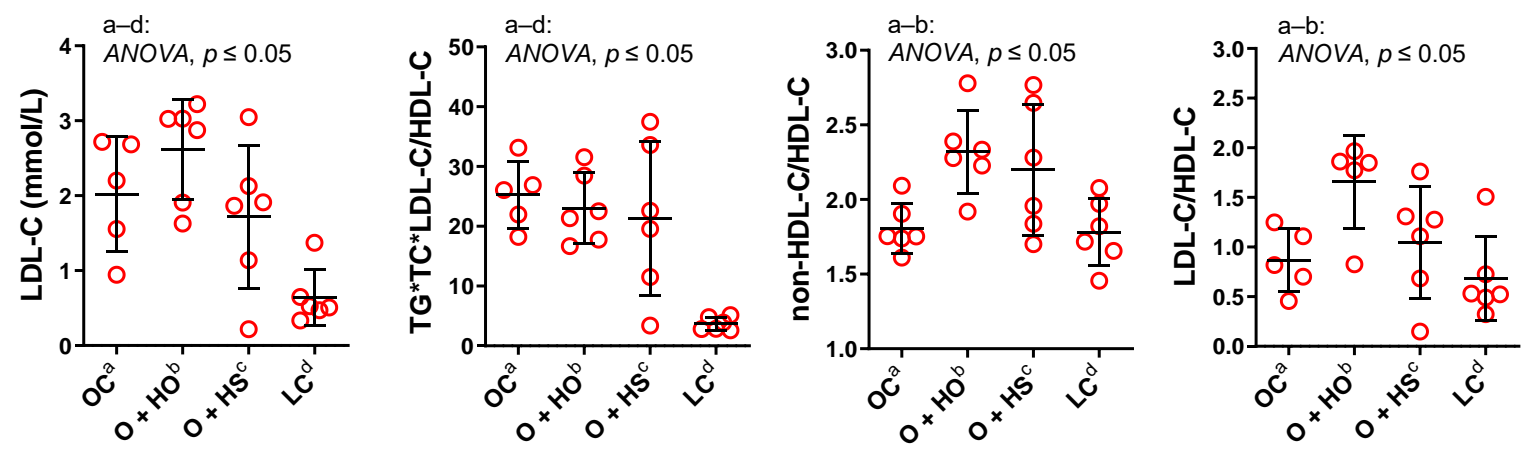

Figure 3. A nontraditional lipid profile (A-H) of 8-week-old lean (LC) and obese (OC) Zucker rats fed a diet containing hemp seed oil (HO) and hemp seeds (HS) for 4 weeks. Values are means $\pm \mathrm{SD}, n=6, p \leq 0.05$ (two-way ANOVA). HO decreased the calculated atherogenic parameters; meanwhile, HS had no such effect.

A

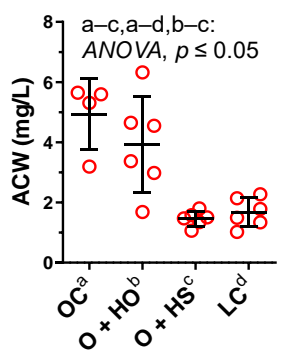

F

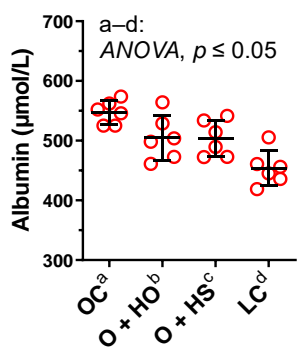

B

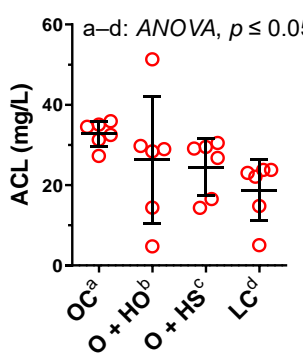

G

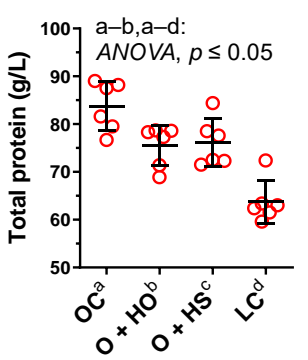

C

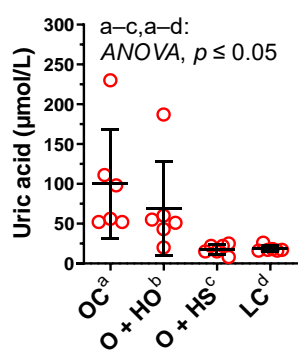

H

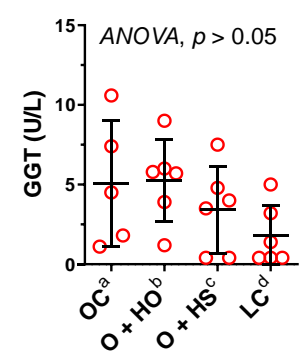

D

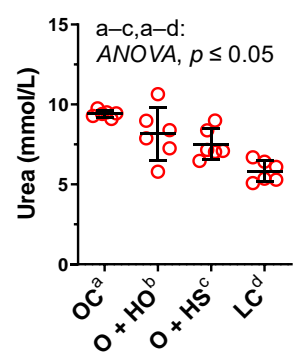

I

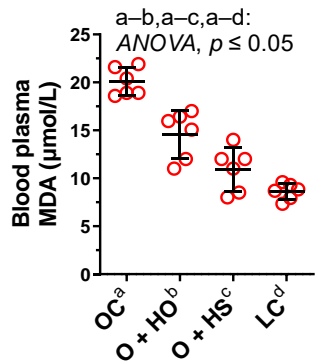

E

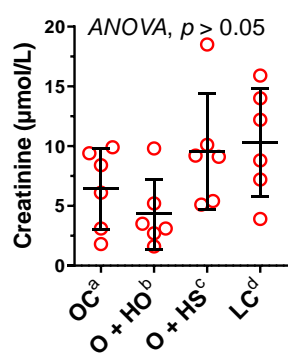

$J$

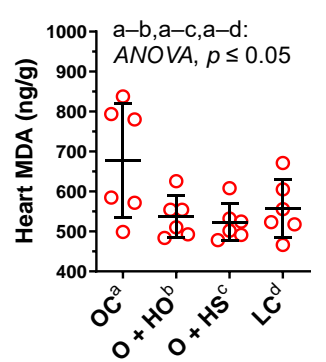

Figure 4. Blood plasma analysis (A-I) and heart malondialdehyde (J) of 8-week-old lean (LC) and obese (OC) Zucker rats fed a diet containing hemp seed oil (HO) and hemp seeds (HS) for 4 weeks. Values are means $\pm \mathrm{SD}, n=6, p \leq 0.05$ (two-way ANOVA). ACW is a marker that distinguishes HO from HS. ACL, antioxidant capacity of lipid-soluble compounds; ACW, antioxidant capacity of water-soluble compounds; MDA, malondialdehyde. 


\subsection{Blood Analysis}

Supplementation with $\mathrm{HO}$ decreased the total protein $(\mathrm{x} 0.90, p=0.05)$, but not the GGT (x1.04, $p=1.00)$, albumin $(x 0.92, p=0.08)$, urea $(x 0.87, p=0.15)$, uric acid $(x 0.69$, $p=0.66)$, and creatinine $(\mathrm{x} 0.67, p=0.84)$. By contrast, HS decreased the uric acid $(\mathrm{x} 0.18$, $p=0.03)$ and the urea $(x 0.80, p=0.02)$. Neither the creatinine $(x 1.48, p=0.63)$, the albumin $(\mathrm{x} 0.92, p=0.08)$, the total protein $(\mathrm{x} 0.91, p=0.07)$, nor GGT $(\mathrm{x} 0.68, p=0.86)$ were modified in a significant way. There was no significant difference between $\mathrm{HS}$ vs. HO in the level of creatinine $(\mathrm{x} 2.22, p=0.21)$, total protein $(\mathrm{x} 1.01, p=1.00)$, albumin $(\mathrm{x} 1.00, p>0.9999)$, urea $(\mathrm{x} 0.92, p=0.67)$, GGT $(\mathrm{x} 0.65, p=0.71)$, or uric acid $(\mathrm{x} 0.26, p=0.25)$; see Figure $4 \mathrm{C}-\mathrm{H}$ and Table S1.

\subsection{Lipid Peroxidation in Blood Plasma and Heart}

Measurement of MDA showed increased lipid peroxidation in OC vs. LC. Supplementation with either HO or HS decreased MDA in blood plasma ( $\mathrm{x} 0.73, p=0.0009$ and $\mathrm{x} 0.54$, $p<0.0001$, respectively, Figure $4 \mathrm{I})$ and in the heart $(\mathrm{x} 0.79, p=0.05$ and $\mathrm{x} 0.77, p=0.0441$, respectively, Figure 4J). There was a significant difference between HS and HO in blood plasma MDA $(x 0.75, p=0.0241)$ but not in the heart $(x 0.97, p=0.6336)$.

\subsection{Oral Glucose Tolerance Test (OGTT)}

The OGTT pointed to the elevation of the blood glucose concentration in OC vs. LC

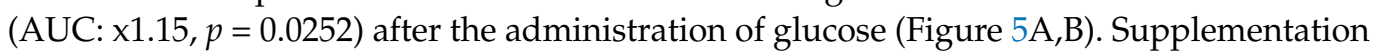
with $\mathrm{HO}$ and HS further elevated the blood plasma glucose (AUC: $x 1.53, p=0.05$ and x1.55, $p=0.05$, respectively).

$A$

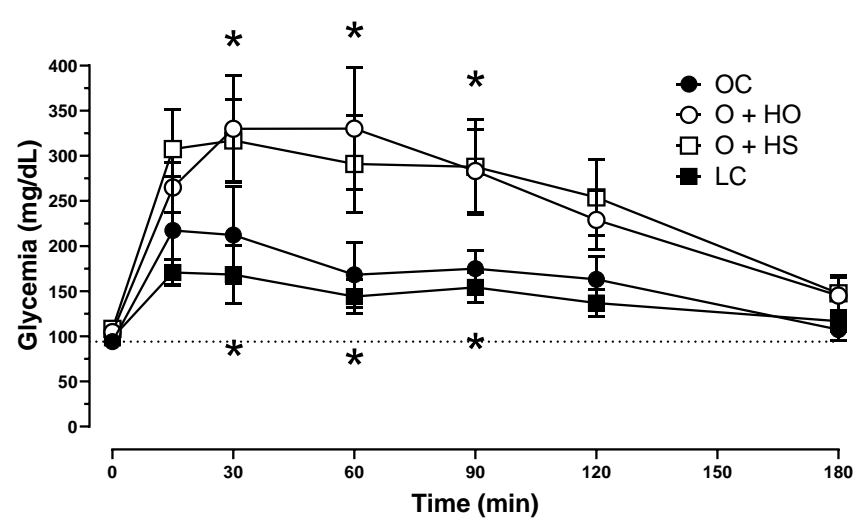

$B$

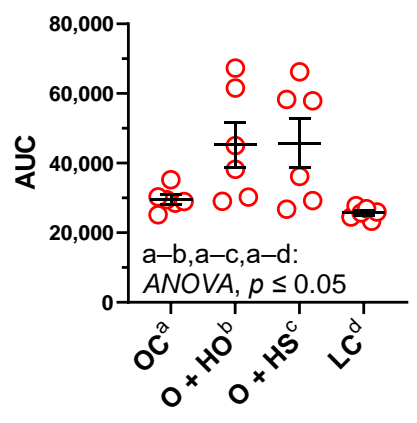

Figure 5. Oral glucose tolerance test (OGTT) of 8-week-old lean (LC) and obese (OC) Zucker rats fed a diet containing hemp seed oil (HO) and hemp seeds (HS) for 4 weeks. Values are means $\pm \mathrm{SD}$, $n=6,{ }^{*} p \leq 0.05$ vs. OC (two-way ANOVA) at 15, 30, 60, 90, 120, and $180 \mathrm{~min}(\mathrm{~A})$, and as area under the curve-AUC (B). HO and HS did not ameliorate the impaired glucose tolerance test.

Blood plasma fasting glucose only tended to be different among the dietary groups $p \geq 0.1054$, with the highest level observed in HS; see Table S1.

\subsection{Blood Pressure Measurements}

The mean arterial pressure (MAP, $x 1.30, p=0.0244$, Figure $6 \mathrm{~A})$ and heart rate (HR, $\mathrm{x} 0.94, p=0.0010$, Figure $6 \mathrm{~B}$ ) were modified in OC vs. LC. Experimental supplementation had no influence on MAP (HO: $\mathrm{x} 0.96, p=0.9501$ and HS: $\mathrm{x} 0.96, p=0.6364$ ) nor on HR (HO: $\mathrm{x} 1.04, p=0.0728$ and HS: $\mathbf{x} 1.02, p=0.4529)$. 

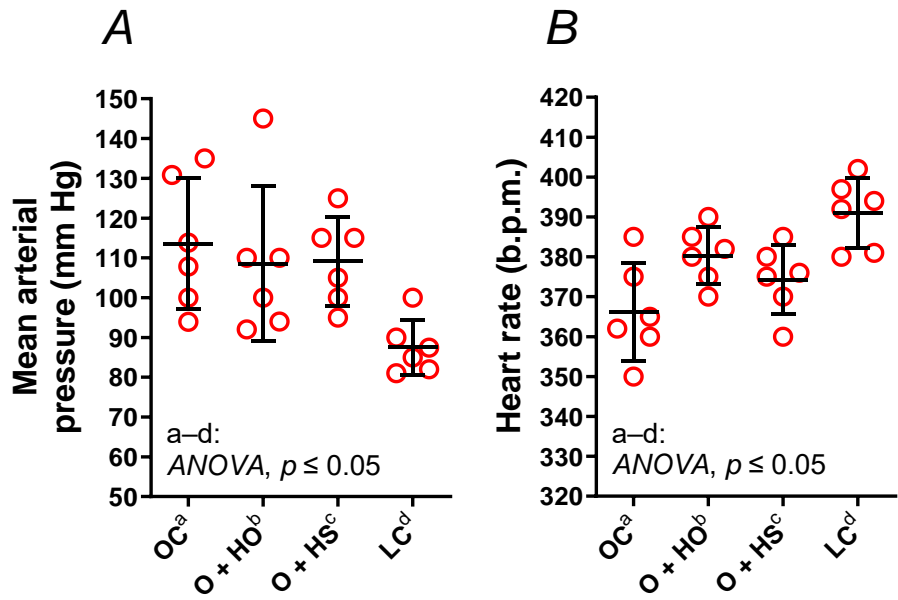

Figure 6. Mean arterial pressure (A) and a heart rate (B) of 8-week-old lean (LC) and obese (OC) Zucker rats fed a diet containing hemp seed oil (HO) and hemp seeds (HS) for 4 weeks. Values are means $\pm \mathrm{SD}, n=6, p \leq 0.05$ (two-way ANOVA). HO and HS had no impact on mean arterial pressure and heart rate.

\subsection{Thromboxane- $A_{2}$ Quantification}

Supplementation with hemp had no significant influence on basal and acetylcholine induced $\mathrm{TxA}_{2}$ release in rat arteries (HO: $\mathrm{x} 0.93, p=0.82$ and $\mathrm{x} 0.96, p=0.87$; HS: $\mathrm{x} 0.88$, $p=0.45$ and $\mathrm{x} 0.92, p=0.43$, HS vs. $\mathrm{HO}, \mathrm{x} 0.95, p=0.93$ and $\mathrm{x} 0.96, p=0.87$, respectively); see Figure 7 and Table S1.

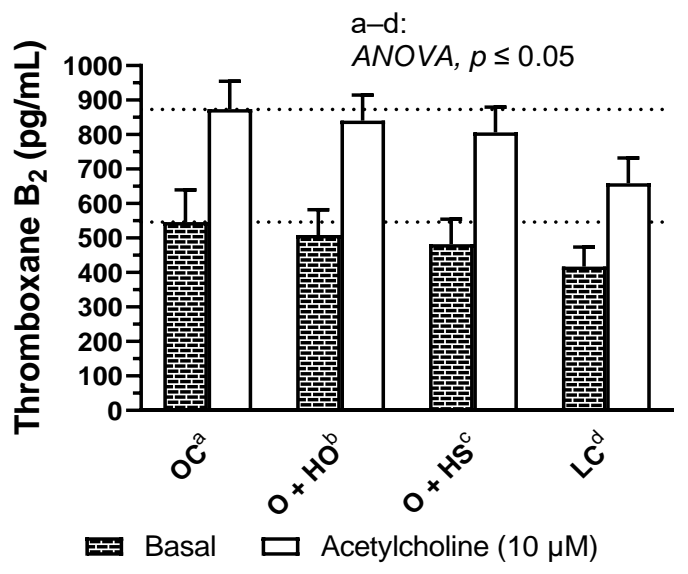

Figure 7. Basal- and acetylcholine-induced $\mathrm{TXA}_{2}$ release from thoracic arteries of 8-week-old lean (LC) and obese (OC) Zucker rats fed a diet containing hemp seed oil (HO) and hemp seeds (HS) for 4 weeks. Values are means $\pm \mathrm{SD}, n=6, p \leq 0.05$ (two-way ANOVA). HO and HS had no influence on basal and acetylcholine-induced $\mathrm{Tx}_{2}$ release in arteries.

\subsection{Vascular Reactivity Studies}

The contractile response to $75 \mathrm{mM} \mathrm{KCl}$ was neither modified by the $\mathrm{HO}(\mathrm{x} 0.95, p=0.33)$ nor by the HS $(\mathrm{x} 1.14, p=0.71)$. No significant difference in the $\mathrm{KCl}$-induced contraction was observed in HS- vs. HO-supplemented rats $(x 1.20, p=0.67)$; see Figure $8 \mathrm{~A}$. In contrast, the noradrenaline-induced contraction was increased in the group of rats supplemented with $\mathrm{HO}(\triangle \mathrm{AUC}, \mathrm{x} 1.59, p=0.01)$ and $\mathrm{HS}(\triangle \mathrm{AUC}, \mathrm{x} 1.54, p=0.03)$, but not in HS vs. HO $(\Delta \mathrm{AUC}$, $\mathrm{x} 0.97, p=0.9$ ); see Figure $8 \mathrm{~B}$. Supplementation with hemp had no significant influence on the vascular contraction induced by U-46619 in obese Zucker rats $(\triangle \mathrm{AUC}, \mathrm{HO} \times 0.87$, $p=0.4$; HS x0.85, $p=0.5$; HS vs. HO x0.97, $p=0.9$ ); see Figure $8 \mathrm{C}$. 
$A$

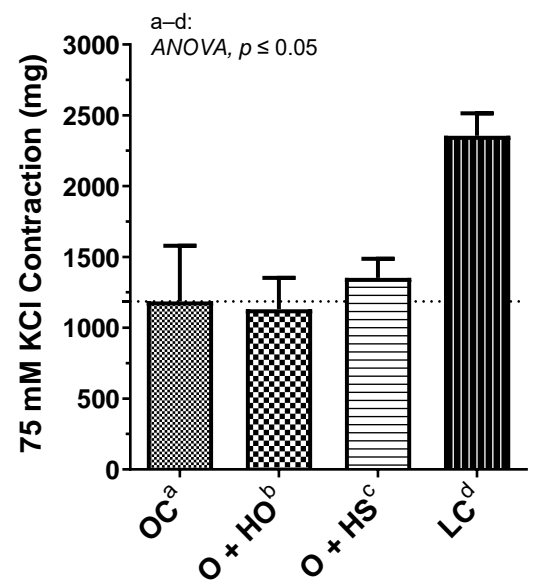

$B$

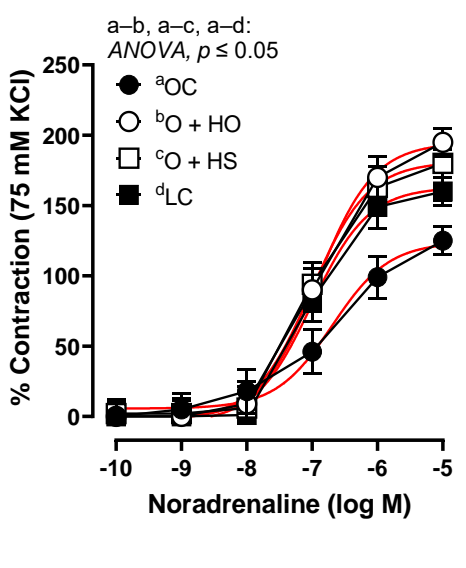

C

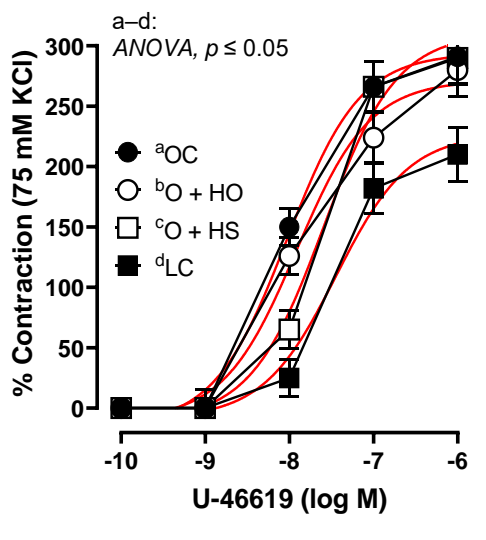

Figure 8. The contractile response of isolated thoracic arteries from 8-week-old lean (LC) and obese (OC) Zucker rats fed a diet containing hemp seed oil (HO) and hemp seeds (HS) for 4 weeks. Vascular contraction was induced by potassium chloride $(75 \mathrm{mM} \mathrm{KCl})(\mathbf{A})$, noradrenaline $(0.1 \mathrm{nM}-10 \mu \mathrm{M})(\mathbf{B})$, and a thromboxane- $\mathrm{A}_{2}$ analog $(\mathrm{U}-46619,0.1 \mathrm{nM}-1 \mu \mathrm{M})(\mathbf{C})$. Results (means $\pm \mathrm{SEM}$ ) are expressed in $\mathrm{mg}$ of tension and as a percentage of the previous tone elicited by $75 \mathrm{mM} \mathrm{KCl}$. $p \leq 0.05$ (two-way ANOVA/Sidak's), $n=6$. HO and HS improved contraction to noradrenaline.

The acetylcholine-induced relaxation was potentiated 1.21-fold by the HS ( $\triangle \mathrm{AUC}$, $p \leq 0.05)$, but not by the $\mathrm{HO}(\triangle \mathrm{AUC}, \mathrm{x} 1.02, p=0.45)$, Figure $9 \mathrm{~A}$. No significant difference was observed in $\mathrm{HS}$ vs. $\mathrm{HO}(\triangle \mathrm{AUC}, \mathrm{x} 1.19, p>0.9)$. In both studied groups, the arteries precontracted with noradrenaline responded in a similar way when subjected to sodium nitroprusside $(\triangle \mathrm{AUC}, \mathrm{HO}, \mathrm{x} 0.86, p>0.9 ; \mathrm{HS}, \mathrm{x} 0.91, p>0.5$; and $\mathrm{HS}$ vs. $\mathrm{HO} \times 1.06, p>0.9)$, Figure $9 \mathrm{~B}$. Relaxant response to pinacidil was shifted to the right $x 1.47$ by the $\mathrm{HO}(\triangle \mathrm{AUC}$, $p \leq 0.01$ ), and $x 1.46$ by the HS ( $\triangle \mathrm{AUC}, p \leq 0.01$ ); however, there was no significant difference in HS- vs. HO-induced relaxation $(\triangle \mathrm{AUC}, \mathrm{x1} .00, p=0.97)$, Figure $9 \mathrm{C}$. Relaxant response to NS1619 was increased $x 69.60$ by the $\mathrm{HO}(\triangle \mathrm{AUC}, p \leq 0.001)$, and $\times 82.29$ by HS $(\triangle \mathrm{AUC}, p \leq 0.001)$, and a significant change was observed in HS vs. $\mathrm{HO}(\triangle \mathrm{AUC}, \mathrm{x} 1.18$, $p \leq 0.05)$; Figure $9 \mathrm{D}$. For the $\mathrm{E}_{\max }, \mathrm{pEC}_{50}$, and AUC, see Table $\mathrm{S} 2$.
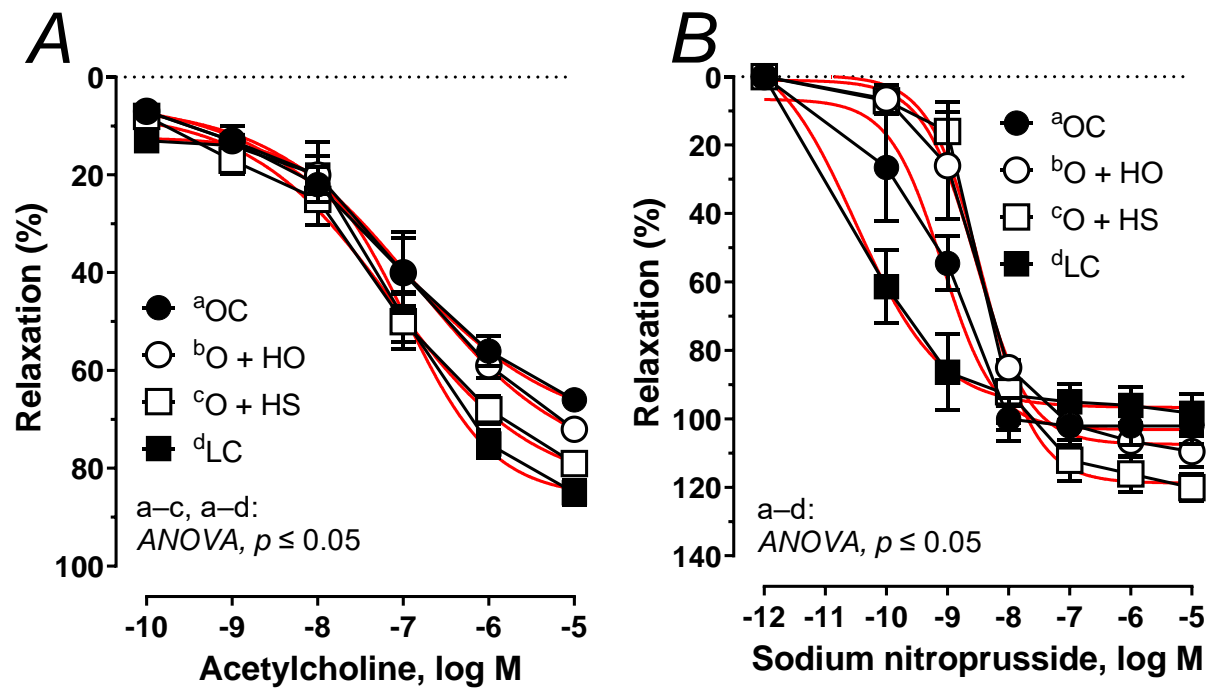

Figure 9. Cont. 

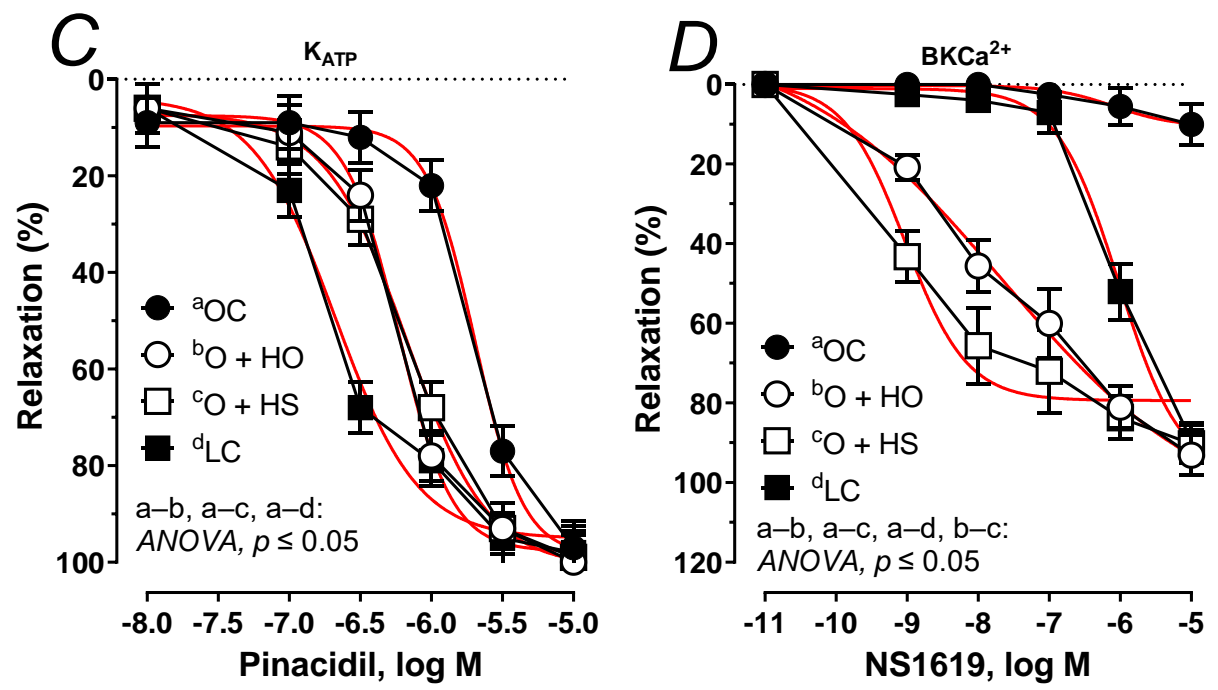

Figure 9. The relaxant response to acetylcholine (A), sodium nitroprusside (B), the $\mathrm{K}_{\mathrm{ATP}}$ channel opener, pinacidil (C), and the BKCa ${ }^{2+}$ channel opener, NS1619 (D) of isolated thoracic arteries from 8-week-old lean (LC) and obese (OC) Zucker rats fed a diet containing hemp seed oil (HO) and hemp seeds (HS) for 4 weeks. Results (means \pm SEM) are expressed as a percentage of the inhibition of the contraction induced by noradrenaline $(0.1 \mu \mathrm{M}), n=6, p \leq 0.05$ (two-way ANOVA/Sidak's). HO and HS improved functioning of potassium channels dependent on ATP and $\mathrm{Ca}^{2+}$. Moreover, HS improved the impaired vascular relaxation to acetylcholine.

\section{Discussion}

Previously, we had reported that ground seeds from dietary hemp (Cannabis sativa L.) more effectively attenuate metabolic disorders compared with the oil fraction from hemp seeds [9]. Now, we have further investigated the influence of dietary supplementation with hemp seeds ( $12 \%$ of diet) vs. corresponding concentration of hemp seed oil ( $4 \%$ of diet) on vascular dysfunction, blood pressure, and heart rate, the blood plasma lipid profile, oral glucose tolerance, antioxidant capacity, and renal functioning in obese Zucker rats, a model of obesity.

As was stated before, experimental supplementation neither modified the body weight gain nor the food intake of supplemented obese Zucker rats [9].

The influence of the oil from hemp seeds on lipid metabolism is well documented, contrary to the effect of the ground seeds, which is poorly studied as of yet. Therefore, we have undertaken further research. Both ground seeds and the oil were able to affect the lipid metabolism (decrease in the plasma HDL cholesterol), although the effectiveness of the seeds was much more indicated (decrease in the plasma total cholesterol). The plasma triglycerides concentration was not significantly decreased by the seeds, but it was by the oil, which is in accordance with our previous results [9]. We have further calculated a nontraditional lipid profile, which is an even better marker of atherogenicity $[14,16,18]$. Surprisingly, the effect of hemp oil was much more pronounced compared to the seeds, as indicated by a decrease in the AIP: $\log _{10}\left(\frac{\mathrm{TG}}{\mathrm{HDL}}\right)$, the cholesterol ratio: $\frac{\mathrm{TC}}{\mathrm{HDL}}, \mathrm{VLDL}$, and by an increase in $\frac{\text { nonHDL }}{\mathrm{HDL}}$ and $\frac{\mathrm{LDL}}{\mathrm{HDL}}$. Neither hemp seeds nor hemp oil improved the impaired glucose tolerance that was induced in the obese group of rats, yet these favorable effects of hemp seeds and oil were not as defined on blood glucose as those on the lipids.

Hemp seeds are a good source of fatty acids (33.2\%), see Table 1 . In our study, the fatty acid profile of the seeds and the oil from hemp was found to be similar. The main PUFAs determined were linoleic acid, $\alpha$-linolenic acid, and $\gamma$-linolenic acid, with an abundance of $\sim 52 \%, 18 \%$, and $4 \%$. Moreover, hemp seeds are also a good source of protein $(26.3 \%)$ and dietary fiber $(27.5 \%)$, which may explain the observed differences in the blood plasma lipids. Highly digestible proteins and dietary fiber can trigger a rise in protein synthesis of 
smooth muscles [19] and increase the gut microbial glycolytic activity: $\beta$-glucosidase as well as $\alpha$ - and $\beta$-galactosidase [9].

In addition, this study is the first to describe the reactivity of isolated thoracic arteries in hemp-supplemented obese Zucker rats. This specific rat model is characterized by a number of metabolic disorders, including vascular dysfunction and increased oxidative stress. Supplementation with hemp seeds and seed oil beneficially potentiated (already decreased, Figure 8B) vasoconstriction in response to noradrenaline. However, this neither changed the membrane depolarization induced by high $\mathrm{KCl}$ nor the response to the thromboxane- $\mathrm{A}_{2}$ analog, U-46619. It is worth mentioning that metabolic dysfunction observed in obese Zucker rats decreased depolarization and enhanced U-46619-induced contraction, as was presented in Figure 8A,C. Moreover, supplementation with hemp did not decrease the thromboxane- $\mathrm{A}_{2}$ level in blood vessels under basal and acetylcholinestimulated conditions in obese Zucker rats.

Next, we studied impaired vascular relaxation observed in obese Zucker rats. The attenuated relaxant response to acetylcholine (Figure 9A) was improved by the seeds but not by the oil. Surprisingly, the vasodilator response to exogenous nitric oxide (which is attenuated in obese Zucker rats (Figure 9B) was not modified with dietary hemp. This indicates that the sensitivity of the smooth muscles of rat thoracic aorta to nitric oxide was not modified during supplementation and that it was the endothelial functioning that was improved by the seeds but not by the oil. In rat thoracic arteries, $\mathrm{K}_{\mathrm{ATP}}$ and $\mathrm{BK}_{\mathrm{Ca}}$ channels are also engaged in vascular tone regulation to compensate for the attenuated vascular relaxation [2]. The relaxant response to the $\mathrm{K}_{\mathrm{ATP}}$ channel opener was downregulated in obese rats, which points to a decreased sensitivity (Figure 9C). Experimental supplementation with hemp improved the impaired functioning of these channels and shifted that response to the left. However, the sensitivity was not fully restored to the level observed in the lean controls. Next, we examined the impaired vasodilator response with a BK $\mathrm{Ca}_{\mathrm{a}}$ channel opener (Figure 9D). In our study, supplementation with hemp increased both the sensitivity and the maximal response, which was more pronounced in rats fed with seeds (increased sensitivity). Our results point to an improvement in the functioning of $\mathrm{K}_{\mathrm{ATP}}$ and $\mathrm{BK}_{\mathrm{Ca}}$ channels in response to the dietary hemp, with a more beneficial effect from the seeds than the oil.

Despite these beneficial effects on the vascular system, neither HO nor HS had any beneficial impact on impaired mean arterial pressure and heart rate of obese Zucker rats.

We noticed an increased plasma antioxidant capacity of lipid- and water-soluble compounds (Figure 4A,B) as well as MDA in the blood plasma and the heart (Figure 4I,J) in obese Zucker rats compared to the lean controls, perhaps as a response to the increased oxidative stress, which up-regulated the mechanism(s) responsible for the antioxidant defense and potentiated lipid peroxidation. Both dietary seeds and the oil decreased the lipid peroxidation in the blood plasma and in the heart. However, the effectiveness of the seeds was more indicated, which was reflected by a decrease in the plasma antioxidant capacity of water-soluble compounds. This was not observed for hemp oil and the plasma antioxidant capacity of lipid-soluble compounds.

The decreased plasma antioxidant capacity of water-soluble compounds by the seeds is associated with the decreased plasma uric acid (Figure 4C), which is strongly hydrophilic, but not with the plasma levels of albumin (Figure 4F) nor bilirubin (data not shown). All these components, together with vitamin $C$, are considered the main blood plasma antioxidants in humans $[20,21]$. Paradoxically, plasma uric acid positively correlates and predicts the development of obesity, hypertension, and cardiovascular disease [21]. Thus, the decreased plasma uric acid by the seeds in the present study can be considered beneficial for the body, especially when looking at its role in the development of gout. Support of this supposition can be found in the study by Opyd et al. [9], who showed that dietary supplementation with hemp seeds improved the antioxidant status of the liver in Zucker rats by increasing glutathione levels and decreasing a marker of lipid peroxidation. This means that a considerable decrease in the plasma antioxidant capacity and uric acid level 
does not automatically exclude benefits coming from hemp seed supplementation to the organ's antioxidant defense system.

Moreover, gamma-glutamyl transferase and blood plasma creatinine were neither modified by obesity itself (Figure $4 \mathrm{E}, \mathrm{H}$ ) nor by hemp supplementation, as opposed to blood plasma total protein level, which was decreased by HO. It is worth mentioning that obesity increased blood plasma albumins, total protein, and urea (Figure 4D,F,G,).

\section{Conclusions}

Dietary supplementation with ground hemp seeds was far more beneficial than with oil, which suggests that the lipid fractions, mainly including PUFAs, are only partially responsible for this effect. In both cases, dietary hemp supplementation was unable to attenuate the development of obesity with its complications, despite the cholesterollowering effect, some improvement in the vascular functioning, and changes in blood plasma antioxidant status.

Supplementary Materials: The following are available online at https://www.mdpi.com/article/ 10.3390/nu13082575/s1, Table S1: Experimental results, Table S2: $\mathrm{E}_{\max }, \mathrm{pEC}_{50}$, and AUC values calculated from cumulative concentration-response curve from thoracic arteries of supplemented rats.

Author Contributions: Conceptualization, A.J. and M.M.; methodology, A.J. and M.M.; software, A.J. and M.M.; validation, A.J. and M.M.; formal analysis, A.J. and M.M.; investigation, A.J. and M.M.; resources, A.J. and M.M.; data curation, A.J. and M.M.; writing—original draft preparation, A.J. and M.M.; writing—review and editing, A.J. and M.M.; visualization, M.M.; supervision, A.J. and M.M.; project administration, A.J. and M.M.; funding acquisition, A.J. and M.M. Both authors have read and agreed to the published version of the manuscript.

Funding: This research was funded by the National Science Centre, Poland, 2016/23/B/NZ9/01012 granted to A.J., and was funded by UWM statutory funding, Olsztyn, Poland, 61.610.007-110 granted to M.M.

Institutional Review Board Statement: This study was approved by the Local Ethics Committee for Animal Experiments (Permission Number: 37/2017, Olsztyn, Poland) according to Directive 2010/63/EU, which conforms to the Guide for the Care and Use of Laboratory Animals (NIH Publications No. 86-26, revised 2014), and was carried out in compliance with the 3Rs rule (replacement, refinement, and reduction).

Informed Consent Statement: Not applicable.

Data Availability Statement: Data supporting reported results can be found in Supplementary Materials.

Conflicts of Interest: The authors declare no conflict of interest. The funders had no role in the design of the study; in the collection, analyses, or interpretation of data; in the writing of the manuscript, or in the decision to publish the results.

\section{References}

1. Stapleton, P.A.; James, M.E.; Goodwill, A.G.; Frisbee, J.C. Obesity and vascular dysfunction. Pathophysiology 2008, 15, 79-89. [CrossRef]

2. Majewski, M.; Jurgoński, A.; Fotschki, B.; Juśkiewicz, J. The toxic effects of monosodium glutamate (MSG)-The involvement of nitric oxide, prostanoids and potassium channels in the reactivity of thoracic arteries in MSG-obese rats. Toxicol. Appl. Pharmacol. 2018, 359, 62-69. [CrossRef] [PubMed]

3. De Artinano, A.A.; Castro, M.M. Experimental rat models to study the metabolic syndrome. Brit. J. Nutr. 2009, 102, 1246-1253. [CrossRef] [PubMed]

4. Majewski, M.; Ognik, K.; Juśkiewicz, J. The interaction between resveratrol and two forms of copper as carbonate and nanoparticles on antioxidant mechanisms and vascular function in Wistar rats. Pharmacol. Rep. 2019, 71, 862-869. [CrossRef]

5. Majewski, M.; Ognik, K.; Juśkiewicz, J. The antioxidant status, lipid profile, and modulation of vascular function by fish oil supplementation in nano-copper and copper carbonate fed Wistar rats. J. Funct. Foods 2020, 64, 103595. [CrossRef]

6. Clarke, S.D. Polyunsaturated fatty acid regulation of gene transcription: A molecular mechanism to improve the metabolic syndrome. J. Nutr. 2001, 131, 1129-1132. [CrossRef]

7. Lunn, J.; Theobald, H.E. The health effects of dietary unsaturated fatty acids. Nutr. Bull. 2006, 31, 178-224. [CrossRef] 
8. Da Porto, C.; Decorti, D.; Tubaro, F. Fatty acid composition and oxidation stability of hemp (Cannabis sativa L.) seed oil extracted by supercritical carbon dioxide. Ind. Crop. Prod. 2012, 36, 401-404. [CrossRef]

9. Opyd, P.M.; Jurgoński, A.; Fotschki, B.; Juśkiewicz, J. Dietary hemp seeds more effectively attenuate disorders in genetically obese rats than their lipid fraction. J. Nutr. 2020, 150, 1425-1433. [CrossRef]

10. Al-Khalifa, A.; Maddford, T.G.; Chahine, M.N.; Austria, J.A.; Edel, A.L.; Richard, M.N.; Ander, B.P.; Gavel, N.; Kopilas, M.; Ganguly, R.; et al. Effect of dietary hempseed intake on cardiac ischemia-reperfusion injury. Am. J. Physiol. Regul. Integr. Comp. Physiol. 2007, 292, 1198-1203. [CrossRef]

11. Girgih, A.T.; He, R.; Aluko, R.E. Kinetics and molecular docking studies of the inhibitions of angiotensin converting enzyme and renin activities by hemp seed (Cannabis sativa L.) peptides. J. Agric. Food Chem. 2014, 62, 4135-4144. [CrossRef]

12. Flores-Sanchez, I.J.; Verpoorte, R. Secondary metabolism in cannabis. Phytochem. Rev. 2008, 7, 615-639. [CrossRef]

13. Majewski, M.; Lis, B.; Olas, B.; Ognik, K.; Juśkiewicz, J. Dietary supplementation with copper nanoparticles influences the markers of oxidative stress and modulates vasodilation of thoracic arteries in young Wistar rats. PLoS ONE 2020, 15, e0229282. [CrossRef] [PubMed]

14. Majewski, M.; Lis, B.; Juśkiewicz, J.; Ognik, K.; Jedrejek, D.; Stochmal, A.; Olas, B. The composition and vascular/antioxidant properties of Taraxacum officinale flower water syrup in a normal-fat diet using an obese rat model. J. Ethnopharmacol. 2021, 265, 113393. [CrossRef]

15. Majewski, M.; Lepczyńska, M.; Dzika, E.; Grzegorzewski, W.; Markiewicz, W.; Mendel, M.; Chłopecka, M. Evaluation of the time stability of aortic rings in young wistar rats during an eight-hour incubation period. J. Elementol. 2019, 24, 677-686. [CrossRef]

16. Majewski, M.; Kucharczyk, E.; Kaliszan, R.; Markuszewski, M.; Fotschki, B.; Juśkiewicz, J.; Borkowska-Sztachańska, M.; Ognik, $\mathrm{K}$. The characterization of ground raspberry seeds and the physiological response to supplementation in hypertensive and normotensive rats. Nutrients 2020, 12, 1630. [CrossRef]

17. Majewski, M.; Ognik, K.; Thoene, M.; Rawicka, A.; Juśkiewicz, J. Resveratrol modulates the blood plasma levels of Cu and Zn, the antioxidant status and the vascular response of thoracic arteries in copper deficient Wistar rats. Toxicol. Appl. Pharmacol. 2020, 390, 114877. [CrossRef] [PubMed]

18. Majewski, M.; Lis, B.; Juśkiewicz, J.; Ognik, K.; Borkowska-Sztachańska, M.; Jedrejek, D.; Stochmal, A.; Olas, B. Phenolic fractions from dandelion leaves and petals as modulators of the antioxidant status and lipid profile in an in vivo study. Antioxidants 2020, 9, 131. [CrossRef] [PubMed]

19. House, J.D.; Neufeld, J.; Leson, G. Evaluating the quality of protein from hemp seed (Cannabis sativa L.) products through the use of the protein digestibility-corrected amino acid score method. J. Agric. Food Chem. 2010, 58, 11801-11807. [CrossRef] [PubMed]

20. Yeni, E.; Gulum, M.; Selek, S.; Erel, O.; Unal, D.; Verit, A.; Savas, M. Comparison of oxidative/antioxidative status of penile corpus cavernosum blood and peripheral venous blood. Int. J. Impot. Res. 2005, 17, 19-22. [CrossRef]

21. Sautin, Y.Y.; Johnson, R.J. Uric acid: The oxidant-antioxidant paradox. Nucleosides Nucleotides Nucleic Acids 2008, 27, 608-619. [CrossRef] [PubMed] 